\title{
TENDÊNCIAS DA POLÍTICA DE ASSISTÊNCIA SOCIAL ${ }^{1}$
}

Maria Carmelita Yazbek

A assistência social no âmbito da Seguridade Social brasileira é o primo pobre, assim como o SUS, conforme afirmou o professor Emerson. Sua inserção na Constituição, expressa, de um certo lado uma mobilização de alguns setores da sociedade, de algumas categorias profissionais, sobretudo dos assistentes sociais, de alguns núcleos de estudos no Brasil como o da UNB e o da PUC São Paulo. Esses núcleos tiveram uma certa interferência na inserção da assistência social na Constituição de 1988, mas essa inserção também vai expressar um contexto mais amplo de transformações societárias sobretudo nas relações de trabalho, no mundo capitalista que vai exigir políticas assistenciais. Isso aconteceu não apenas no Brasil, mas no mundo todo. Na Europa, a assistência social também vem ganhando uma certa visibilidade como política.

Mas, eu prefiro aqui enfatizar o significado da inserção da assistente social do ponto de vista das lutas sociais, no âmbito da ampla movimentação da sociedade que vai permitir criar para a assistência social brasileira até então muito mais um conjunto de práticas de benemerência, uma nova matriz, uma nova condição, uma nova visibilidade. Eu entendo que a Constituição e depois a Lei Orgânica da Assistência criam para a assistência social uma nova matriz - eu tenho chamado assim - que permite a passagem da assistência social para um campo novo, o campo do direito, o campo da universalização dos acessos, da responsabilidade do Estado perante as questões da pobreza e da exclusão, o campo da política pública. É um trânsito difícil: o trânsito das práticas de benemerência, filantrópicas, assistencialistas, para o campo das políticas públicas. A inserção da assistencia social na Seguridade traz para essa política uma nova visibilidade, uma nova inserção, trazendo-a para o campo da proteção social. Assim, a Assistência Social articulada à outras políticas no campo social, volta-se à garantia de direitos e de condições dignas de vida para a população brasileira. Nesse sentido também, com essa inserção na seguridade eu entendo que a assistência social expressa também o reconhecimento público da legitimidade da

\footnotetext{
${ }^{1}$ Mesa Redonda Assistência e Previdência: Caminhos e tendências no XX Ciclo de Debates do Serviço Social do Hospital das Clínicas da UNICAMP. Expositores: Professor Dr. Wilson Cano do Instituto de \begin{tabular}{lllll}
\hline Serviço Social \& Saúde & Campinas & v. 3 & n. 3 & p. 1-94 Maio 2004
\end{tabular}
} 
demanda e das necessidades dessa população que dela se utiliza. Mais do que isso, a assistencia social configura-se em um espaço para que essa população amplie o seu protagonismo e a sua presença, uma vez que constitucionalmente se coloca a necessidade da participação dos usuários na gestão do sistema descentralizado e participativo de assistência.

Realmente, isso é uma novidade neste campo, trazer esse conjunto de práticas, para um outro patamar, patamar da política que se expressa num certo caráter civilizatório, que está presente na consagração de todos os direitos sociais, que vai exigir que a provisões assistenciais sejam colocadas no plano das garantias de cidadania, dos direitos sociais sobre a vigilância do Estado.

Esta lei inova e a Constituição também inova ao afirmar para assistência social um caráter não contributivo, pois ela é uma política pública não contributiva. Inova ainda ao afirmar a necessária integração das políticas sociais na resposta às necessidades dessa população. Ela inova com a participação da população no controle social, na gestão e na execução dessa política, ela desmonta um antigo Conselho Nacional de Serviço Social, um órgão clientelista e cartorial que era objeto no momento da promulgação da lei, de processos contra corrupção. Isso saía o tempo todo nos jornais, entidades fantasmas, entidades “Pilantrópicas”, etc.

A LOAS cria Conselhos Municipais, Estaduais e o Conselho Nacional de Assistência Social, órgãos paritários com representação do governo e da sociedade, com a presença dos trabalhadores do setor da assistência social e dos seus usuários. Sem dúvida, para os que trabalham há muitos anos como eu na assistência social uma mudança absolutamente relevante, uma mudança substantiva na concepção da assistência social, uma definição legal que permite o trânsito da assistencia social do assistencialismo, do clientelismo de sua tradição de não-política para o campo da política pública de direitos, o que não é pouco.

E, como uma política pública ela passa a ser um espaço de defesa e atenção dos interesses e necessidades sobretudo dos segmentos mais empobrecidos da sociedade, aquela

Economia da UNICAMP e Professora Dra. Maria Carmelita YazbeK Coordenadora da Pós-Graduação em Serviço Social da PUC São Paulo.

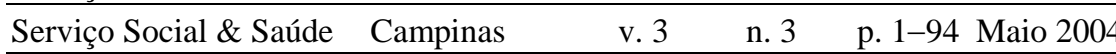


população que vive em extremas condições de pobreza e exclusão. Essa política vai ser uma forma de proteção social, de combate à subalternidade, de combate à discriminação que não é só econômica. Ela é econômica, sobretudo, mas é cultural e política. É uma política que vai oferecer algumas garantias à população, algumas seguranças utilizando uma expressão da Aldaíza Sposati que amanhã estará aqui com vocês, ela oferece algumas seguranças que cobrem ou que deveriam cobrir, reduzir ou prevenir algumas situações de risco e de vulnerabilidade social em que vive essa população.

Ela atende às necessidades emergentes ou permanentes constantes decorrentes de problemas pessoais ou de problemas sociais estruturais dessa parcela da população.

Nesse sentido a assistência social é uma política que vai dar a medida do compromisso social do Estado exatamente porque ela é a fundo perdido, não há obrigação da contribuição por parte dessa população, mas há o direito assegurado. Essa compreensão da assistência social como um campo de efetivação de direito, como uma política estratégica, não contributiva, voltada para a construção dos chamados “mínimos sociais” de inclusão, conforme consta na lei. Mínimos entendidos aqui não como mínimos que nivelem por baixo, mas como um patamar de qualidade de vida e dignidade de vida abaixo do qual nenhum cidadão brasileiro deveria estar colocado. Então ela aponta a universalização do acesso aos direitos que ela garante, ela busca romper com o clientelismo, com o assistencialismo que historicamente caracterizam não apenas a política de assistência social nesse país, mas as políticas sociais de modo geral. A política brasileira tem essa herança cultural pesada do clientelismo, da tutela, do apadrinhamento, do favor. É claro que nas ações assistênciais esse peso é maior ainda porque essas ações passam pela oferta de algum recurso, de algum serviço, de algum benefício.

Nesse sentindo ela rompe com aquela idéia emergencial de dizer que assistência é um pronto socorro social. É um plantão nas situações emergenciais para distribuir cestas, auxílios financeiros e se pensa a assistência como uma política de maior consistência, com programas, serviços, projetos, uma política que deve ser pensada sempre na relação com outras políticas sociais, e que apresenta um novo desenho institucional caracterizado pelo comando único que aliás não vem sendo cumprido nesse país em cada esfera 
governamental e funcionando como uma estratégia de inclusão e de atenção a seus usuários.

Claro que essa política é impensável sem os fundos: o fundo nacional de assistência, os fundos estaduais de assistência, os fundos municipais de assistência. E também ela é impensável sem o orçamento público. O sistema de descentralização funciona, tem funcionado de forma geral, como uma forma de reordenar essas políticas, de abrir um espaço para participação de seus trabalhadores, de seus usuários reconhecendo aí as particularidades de cada local onde ela se desenvolve. É no cotidiano do município, no cotidiano do nível local que o cidadão consegue avaliar a qualidade do serviço social que recebe: se o abrigo dos idosos funciona com dignidade, se o lar, se a creche e se as atenções a adolescentes em riscos, se a maternidade está funcionando de fato com qualidade.

Então, a proposta legal de descentralizar traz consigo, a qualificação democrática. A importância dessa dimensão no controle social, da presença da população acompanhando o serviço, avaliando os serviços, fortalecendo a experiência participativa e a cidadania no nível local, permitindo uma ação fiscalizatória mais próxima, mais perto da vida do cidadão.

Com esta recomposição legal também as tradicionais entidades prestadoras de assistência social, a gente sabe que isso não é uma novidade neste país, onde já em 1530 temos a primeira Santa Casa que se coloca como entidade filantrópica. Esta rede passa a ser submetida a um outro tipo de controle, porque no momento em que ela é considerada parte do sistema descentralizado e participativo de assistência social, ela está sujeita a fiscalização dos conselhos de assistência, ao controle público. Ela tem que ser convalidada como uma política pública, pelos gestores, pelos Conselhos e pelo nível do próprio Governo Federal porque essas relações são mediadas pelo acesso ao fundo público. No momento em que uma entidade privada acessa ao fundo público ela presta serviços programaticamente em nome da política maior onde ela está inserida. Passa a compor o sistema na medida em que ela se compromete com as diretrizes e aquilo que está previsto na legislação que regulamenta a assistência social no país.

Essa é a proposta que sempre gosto de colocar para fazer um balanço do quanto conseguimos avançar nesses 10 anos, - 10 anos após a LOAS. Considero que esse é um

\begin{tabular}{lllll}
\hline Serviço Social \& Saúde & Campinas & v. 3 & n. 3 & p. 1-94 Maio 2004 \\
\hline
\end{tabular}


momento importante em que nós podemos fazer um balanço sobre essa política e projetá-la para o futuro. Começo afirmando que esta política vem enfrentado algumas das grandes dificuldades, sobretudo no âmbito federal. É lamentavel fazer essa afirmação porque sou do Partido dos Trabalhadores e se há uma área que está absolutamente complicada no atual governo é a área da assistência social que passa de uma Secretaria a Ministério, mas não faz jus a Ministério. Eu temo inclusive pela manutenção desse Ministério. Acho que se a ministra cair, leva o Ministério junto tal a dificuldade em levar um projeto conforme vem sendo construído nesses 10 anos.

Nós passamos 10 anos construindo um projeto para área da Assistência Social no país. E, na atual conjuntura vemos esse projeto emperrar e pior, aos poucos ser substituído por uma visão conservadora sobre a assistência social, sobre as famílias pobres, culpandoas pela sua pobreza. Ou seja, aquilo que se construiu ao longo de 10 anos, parece estar em uma posição bastante complicada. Esse ano nós temos a IV Conferência Nacional de Assistência Social e eu acho que esta Conferência vai ser crucial do ponto de vista da nossa sociedade civil organizada que deverá colocar claramente as suas posições.

Mas, sobre esses 10 anos de balanço temos algumas rápidas reflexões a partilhar com vocês. A primeira constatação é que nesse 10 anos, que foram 10 anos de questionamento do clientelismo, do padrão de gestão conservadora dessa política e da identificação histórica da assistência social com a filantropia, ainda me parece que essa é uma questão não superada na assistência social. A tendência a ver a assistência social como ação filantrópica, assistencialista e tuteladora ainda é um objeto de questionamentos e reivindicações nas Conferências Municipais e nas Conferências Estaduais em andamento. O que estamos percebendo é que o protagonismo da população vem sendo muito pouco colocado nesse processo. A luta continua e na verdade sua grande tendência ainda é lutar para que o reconhecimento do direito seja a medida da negociação e da liberação no campo dessa política. Não há outra medida ainda. Nossa luta é para que o direito seja a medida. Não dá para negociar direito, esta luta então continua.

Uma outra constatação nesses 10 anos e que foi observada nas três Conferências de Assistência Social anteriores é a presença da perspectiva focalista dessa política que acompanhou 10 anos do governo Fernando Henrique e que não se rompeu. A assistência

\begin{tabular}{lllll}
\hline Serviço Social \& Saúde & Campinas & v. 3 & n. 3 & p. 1-94 Maio 2004 \\
\hline
\end{tabular} 
social ainda é uma política focalizada, seletiva, pobre para o pobre. Os critérios de seleção e avaliação ainda permanecem muito focalizados nos mais pobres, nos mais vulneráveis, o que vem restringindo projetos mais renovadores e/ou criativos para essa política.

Há experiências em municípios no país muito interessantes, mas em âmbito nacional a coisa está muito complicada. Ainda, não temos ações integradas, ações intersetoriais, definições de padrões de qualidade. Não temos indicadores de avaliação, porque nós lidamos com dados, porque nós não temos padrões objetivos para avaliar por exemplo o que é um bom centro de lazer para juventude, o que é um abrigo para crianças e adolescentes em risco, o que é um abrigo para idosos, ou um abrigo para população moradora de rua.

O que se observa é que ainda não temos padrões ou indicadores claros, não temos definição concreta do que é uma boa ação intersetorial. A intersetorialidade é frágil, limitada. E a proteção social ainda é vista como benevolência de Estado ou da sociedade.

Um outro ponto que acho que cabe ser discutido neste balanço, e que ainda se coloca como uma agenda, é a questão da construção e mecanismos públicos e democráticos de regulação e de controle social. Tal e qual foi apresentado hoje aqui em relação à saúde sobre o SUS que deve ser construído a cada dia, o sistema descentralizado e participativo de assistência social no país exige ainda a organização de um SUAS (Sistema Unificado de Assistência Social) como parte do processo de construção de mecanismos públicos de regulação e de controle para esta área. Como é que nós vamos fiscalizar e acompanhar? Como é que nós vamos criar parâmetros, sobretudo lembrando que o parâmetro é o direito. Não tem outra medida de negociação dos interesses dessa população que é uma população sem voz, que não existe.

Outro aspecto que percebemos ligado a este é a ausência de conhecimento desses brasileiros. Quem são eles? Em que território habitam, como vivem? A gente às vezes pergunta como é que alguém pode, para receber o Beneficio de Prestação Continuada, seja idoso ou o portador de deficiência, viver com um quarto do salário mínimo per capta familiar. Devo perguntar: o que é isso em matéria de recurso para sobreviver? Que arranjos essa população constrói? Há ainda um frágil conhecimento e um conhecimento cheio de preconceitos dessa população, discriminatório, não só pelo seus hábitos de vida, pelas suas 
crenças, seus valores. É uma população que vive um conjunto muito grande de discriminações.

Um outro ponto que cabe avaliar e pensar nesse momento de construir uma agenda são os impactos dessa política sobre a possível inclusão/exclusão dessa população. Até que ponto a assistência social vem funcionando como um mecanismo de inclusão social? Sabemos que os limites entre inclusão e exclusão são difusos, contraditórios, subordinados a interesses econômicos. Sabemos que a assistência pode ser um mecanismos de inclusão, mas ela pode ser um mecanismos de reiteração total da exclusão social. Ela pode criar o lugar dos pobres: são aqueles que tem o programa lá de renda mínima, aqueles que recebem a cesta. É como se você cindisse a sociedade brasileira o que é cidadão, o que participa das políticas, etc. e o que está lá sobrante. Essa contradição na assistência social permanece. É ela uma política ambígua porque tanto você pode oferecer ajuda para obter a subserviência, a lealdade, como pode emancipar. E isso na história política brasileira não foi superado por causa da LOAS, sabemos disso. A assistência ainda é troca, e moeda de favor. Quando o poder público negocia cargos, oferece a assistência social (porque qualquer um pode fazer.) Em São Paulo foi assim no início da gestão da prefeita Marta Suplicy. Em função de alianças políticas devia dar uma Secretaria para o PSB. Deu a Assistência Social para Evilásio Faria, um médico de boa vontade, mas que não sabia nem o que era assistência social. Esse traço é forte nessa política, como se fazer algo pelos pobres fosse coisa que qualquer um pode fazer, reiterando ainda um caráter atrasado, subserviente exigindo subserviência dessa população o que é um aspecto muito delicado ainda nessa política.

Entendo que a assistência social tanto pode matar a cidadania, como ser um espaço para o protagonismo de seus usuários e uma forma de organização dessa população, que é realmente uma população destituída de poder, de trabalho, de informação, de direito, de oportunidades, de esperanças, e vive em grande parte sob condições muito restrita, muito miserável e submersa numa sociedade que a desqualifica, que a constitui como "cidadãos às avessas” (pela negativa). População que encontra inúmeros clichês para designá-la: como “inadaptados”, “casos sociais”, etc.

\begin{tabular}{lllll}
\hline Serviço Social \& Saúde & Campinas & v. 3 & n. 3 & p. 1-94 Maio 2004 \\
\hline
\end{tabular} 
E nós sabemos também que no atual contexto, que foi rapidamente assinalado pelo professor Emerson e pelo professor Wilson Cano, que convivemos com os impactos destrutivos das atuais transformações societárias, empurradas pelos interesses da mundialização do capital. Esses processos vão deixando suas marcas sobre os trabalhadores e sobretudo para aqueles que não conseguem se inserir no trabalho, os que vivem desempregados ou que têm um trabalho intermitente, precário sem nenhuma garantia, os que vivem sem teto, que vivem sem terra, os que envelhecem sem qualidade, os que moram em habitações insalubres, os que tem a saúde fragilizada, que partem pelos caminhos da droga, os que convivem com a AIDS, a prostituição, com o trabalho infantil, com alimentação insuficiente, com a fome, com o cansaço, com as humilhações, com o fanatismo. Nós lidamos com as explicações mágicas sobre a realidade. Hoje está na Folha de São Paulo: o censo das favelas em São Paulo é uma coisa assustadora! Somos os campeões! É uma população sujeitada que convive cotidianamente com a violência e tantas outras situações que encontramos cotidianamente na experiência profissional. São situações sociais limites de nossa sociedade. O limite da condição de humanidade. São essas situações que deveriam ser alvo de políticas qualificadas de proteção e de políticas emancipatórias. Em algumas situações temos a ofertar só proteção: o idoso, o portador de deficiência. Situações em que o direito é a proteção.

Nós sabemos então que esses são desafios da assistência social: criar possibilidades de participação para está população, oferecer proteção e possibilidades de protagonismo. Um meio para isso é a criação da rede de entidades, fortalecendo a perspectiva pública, fortalecendo o direito dos cidadãos.

A ação em rede não existe praticamente na maior parte dos municípios brasileiros, trata-se de uma ação consertada, articulada. As entidades brigam pelo pobre: “esse é o meu pobre” o “outro é o seu pobre” Que dizer? Não há uma ação concentrada, não há cadastros unificados. Não há equipamentos de retaguarda, não há instituições de retaguarda para, por em proteção, por exemplo, as crianças vítimas de violência, as mulheres, os idosos que também são vítimas de violência. Não há referências sobre a rede pública, sobre o que é por exemplo um bom abrigo. A impressão é que a assistência social fica apenas nas mãos das entidades privadas e o Estado está omisso.

\begin{tabular}{lllll}
\hline Serviço Social \& Saúde & Campinas & v. 3 & n. 3 & p. 1-94 Maio 2004
\end{tabular} 
Nesses tempos em que cresce o chamado "terceiro setor" esses dados aumentam nossas preocupações porque a fiscalização das ações sociais do chamado terceiro setor, sobretudo, quando ela é desenvolvida com esse segmento mais vulnerabilizado tem sido difícil. Os Conselhos não estão conseguindo acompanhar. Em resumo, 10 anos depois a gente ainda vive muita sobreposição de ação, muita pulverização, muita descontinuidade.

A afirmação do professor Emerson, de que devemos criar sistemas capazes de atravessar governos e institucionalmente capazes de garantir algumas coisas, independentemente dos governos, é fundamental. De todo modo, eu diria que as avaliações, mostram como tem sido difícil essa tarefa, que as ambigüidades ainda marcam esta área, e há sobretudo uma grande dificuldade de trazer para a esfera pública a questão da pobreza e da exclusão.

Eu tenho muitas críticas ao Programa Fome Zero, mas eu acho que uma qualidade ele tem. Quando foi lançado trouxe para discussão pública que neste país há fome, que a pobreza é uma questão pública desta nação. Não foi muito além disso, da publicização da questão.

O grande desafio que se coloca para assistência social é trazer para a esfera pública a pobreza, a exclusão, transformando o que é garantido constitucionalmente em campo de exercício participativo sobretudo dos segmentos subalternizados e excluídos. Claro que nós estamos entrando na contra mão da história, porque nós entramos numa dinâmica, em que há prevalência da esfera econômica sobre o social. Isso é muito forte.

A gente rema meio na contra mão defendendo o social, porque há uma absoluta subordinação do social ao econômico, aos ajustes estruturais da economia. A lógica é assim: se sobrar a gente cuida do social, porque primeiro é o ajuste. Acho que os dados apresentados aqui na área da própria previdência pelo professor Wilson Cano mostram que a primeira subordinação, é ao processo de ajuste, o que vem desmontando direitos trabalhistas, direitos sociais de modo geral. Então, num certo sentido, iniciativas nessa vertente, nessa tendência, de iniciativa de contra desmanche, não tem sido fáceis e isso é um desafio por várias razões.

\begin{tabular}{lllll}
\hline Serviço Social \& Saúde & Campinas & v. 3 & n. 3 & p. 1-94 Maio 2004 \\
\hline
\end{tabular} 
A primeira delas, já mencionei aqui, é o fato da histórica vinculação da assistência com a filantropia. Isso dificulta, cria um confronto entre práticas, assentadas no reconhecimento de direitos e práticas de favor.

E a segunda dificuldade é a expansão do terceiro setor, que despolitiza o trabalho social e valoriza o trabalho voluntário. A desigualdade é despolitizada. Ela não é tratada como uma questão de uma sociedade cindida e divida em classes.

A desigualdade passa a ser um dado administrativo que pode ser tratada pela filantropia. O que se observa é que a articulação histórica entre o trabalho, a proteção social e os direitos que constituiu o chamado Estado de Bem Estar, - que a gente sabe nem chegou até aqui - ela está em transformação, ela está encolhendo o mundo público. Encolhe-se o mundo público, o cidadão é o bem sucedido no mundo privado mercantil. Evidencia-se a incompatibilidade entre ajustes estruturais da economia e investimentos sociais do Estado.

Essa incompatibilidade ainda é mais complicada nos tempos de hoje porque ela é referenciada, é apoiada no discurso neoliberal que defende o dever moral de prestar socorro aos pobres e o dever humanitário, desde que isso não seja considerado direito social. Isso dificulta passar para a esfera pública essa proposta. O que a gente está constatando é que os programas sociais do atual Ministério - Ministério da Assistência Social - e, inclusive o próprio Fome Zero, essa lógica permanece.

A tentativa de unificar os cartões talvez seja um primeiro passo, mas ela é uma tentativa técnica fora de uma política. Onde está a política nacional? Não são observadas propostas que rompam com a ótica seletiva, emergencial, com ações focalizadas, paliativas, assistencialistas em andamento na sociedade. As inovações parecem estar apenas no âmbito de alguns municípios.

Me parece que o maior desafio, e esse é para terminar mesmo, é colocar na esfera pública, o direito que todo cidadão brasileiro tem de ver atendidas as suas necessidades sociais. Quando falo público, estou falando da perspectiva da universalidade, dos interesses coletivos. Estou falando de uma visibilidade e de uma transparência pública. Qualquer cidadão deveria poder acessar, no mínimo pela internet, os dados das políticas públicas desse país. Elas teriam que ser transparentes, pois envolvem o controle social, a

\begin{tabular}{lllll}
\hline Serviço Social \& Saúde & Campinas & v. 3 & n. 3 & p. 1-94 Maio 2004
\end{tabular}


participação da sociedade e a democratização. Neste âmbito a gente observa em andamento, em alguns municípios iniciativas que estão buscando deter esse processo de privatização do público que também foi referido aqui pelo professor Emerson como uma das tensões do SUS.

Em alguns municípios é possível observar essa busca pela recuperação do protagonismo do Estado nesta área, de sua responsabilidade. Quando falo do Estado, falo do nível federal, do nível estadual e do nível municipal. É o Estado, o regulador, o financiador, o provedor e o gestor principal dos serviços sócio-assistenciais.

Há muito para fazer, sem nenhuma ilusão, porque obviamente diante da desigualdade, diante da pobreza, da subalternidade que vive a população brasileira, as políticas sociais, em particular essa que nós estamos colocando em debate tem limites, tem constrangimentos claríssimos de ordem estrutural que vão gerar a sua baixa efetividade e seu baixo resultado sem ultrapassar esses limites.

Pensar que das políticas sócio assistenciais, e apenas delas resultem melhorias no bem estar social desta população é ilusório e ineficaz. Porque há uma imensa fratura entre o que é anunciado na Constituição, nos nossos projetos, nas nossas Conferências e a realização concreta do direito. Uma coisa é o anuncio do direito, outra coisa é sua realização concreta, sobretudo porque o caráter, cumulativo que está presente nos riscos e vulnerabilidades que marcam a vida dessa população é um caráter que não será facilmente rompido, ou seja, não é pela via das políticas sociais, que a sociedade vai se alterar, mas obviamente sabemos que essas políticas sobretudo nesta estruturação atual expandem direitos. Obrigada. 
